\title{
EFFICIENT POWER OSCILLATION DAMPING CONTROL BY ADAPTIVE NEURO FUZZY CONTROLLER BASED POWER SYSTEM STABILIZER
}

\author{
Shubi Sharda ${ }^{1}$, Geoffrey Eappen ${ }^{2}$ \\ ${ }^{1}$ M.Tech Scholars( Power Electronics), Department of Electronics and Communication Engineering, School of \\ Engineering and I.T., Mats University, Aarang - Kharora Highway, Aarang, Raipur, (C.G.), India \\ psharda750@gmail.com \\ ${ }^{2}$ Assistant Professor, Department of Electronics and Communication Engineering, School of Engineering and I.T., \\ Mats University, Aarang - Kharora Highway, Aarang, Raipur, (C.G.), India \\ geofz121@gmail.com
}

\begin{abstract}
Low frequency Inter-area oscillations are undesirable which affects the goals of maximum power transfer and optimal power flow. Power system stabilizers can be added to the automatic voltage regulators on the generators to reduce the effect of low frequency inter area oscillation. Different types of power system stabilizers are developed to reduce low frequency inter area oscillations inter but the area is still open for the efficient power stabilizer, for handling the power oscillations without increasing the system controller complexity. This paper presents a way to improve the dynamic stability of interconnected power systems by damping of inter area oscillations in two area four machine power system by designing of Adaptive Neuro Fuzzy Inference System based controller. The implementation is done with the Simulink of MATLAB 2012(b).The obtained results shows that ANIFS-PSS is capable of damping power oscillations in multi area system.
\end{abstract}

Keywords: Multi Area Machine System, Power Oscillation Damping, ANFIS Controller, Power System Stabilizer PSS

\section{INTRODUCTION}

System events when coupled with a poorly damped electric power system causes Inter area power oscillations. Large systems with group of generating lines which are connected by weak tie lines consists of oscillations. Group of generators on one side of tie lines oscillating against groups of generators on the other side consists of low frequency modes ranging from $0.1 \mathrm{~Hz}$ to $0.8 \mathrm{~Hz}$.Sub-optimal power flow and ineffective operation of grid are caused by undesirable low frequency oscillations. Therefore it is important to stabilize these low frequency oscillations.

The dynamic stability of power systems can be increased by the help of power system stabilizer which damps out the low frequency oscillations. Due to non-linearity of power systems, exact mathematical model of system is difficult to obtain. Optimum damping to the system oscillations under wide variety in system conditions and parameters can be provided by fuzzy logic based PSS ,adaptive self tuning artificial neural network. Since power system are very large , geographically distributed therefore it is very difficult to solve problems of low frequency oscillations. More effective optimization technique should be utilized to take full advantage in simplifying the problems and its implementations [1-5].
This paper presents the effective and fast damping of inter area power oscillation and improved dynamic stability of interconnected power systems by designing of an ANFIS controller for damping low frequency power oscillations in two area four machine system.

\section{Two Area Four Machine Test System}

In MATLAB 2012(b) test system is available consisting of two (fully) symmetrical areas which are linked together by two tie line $230 \mathrm{KV}$ lines of $220 \mathrm{Km}$ length shown in figure 1. This test system was designed to study the low frequency electrochemical oscillations in large power systems. Each area of test system consists of two identical round rotor generators rated 20KV/900MVA. The parameters of synchronous machines are same except for the inertia in area 1 is $\mathrm{H}=6.5 \mathrm{~s}$ and inertia for area 2 is $\mathrm{H}=6.175 \mathrm{~s}$. Thermal plants having identical speed regulators are further assumed at all locations, in addition to fast static exciter with a 200 gain. The load is represented as constant impedance and spilt between the areas [1,11, and 12]. 


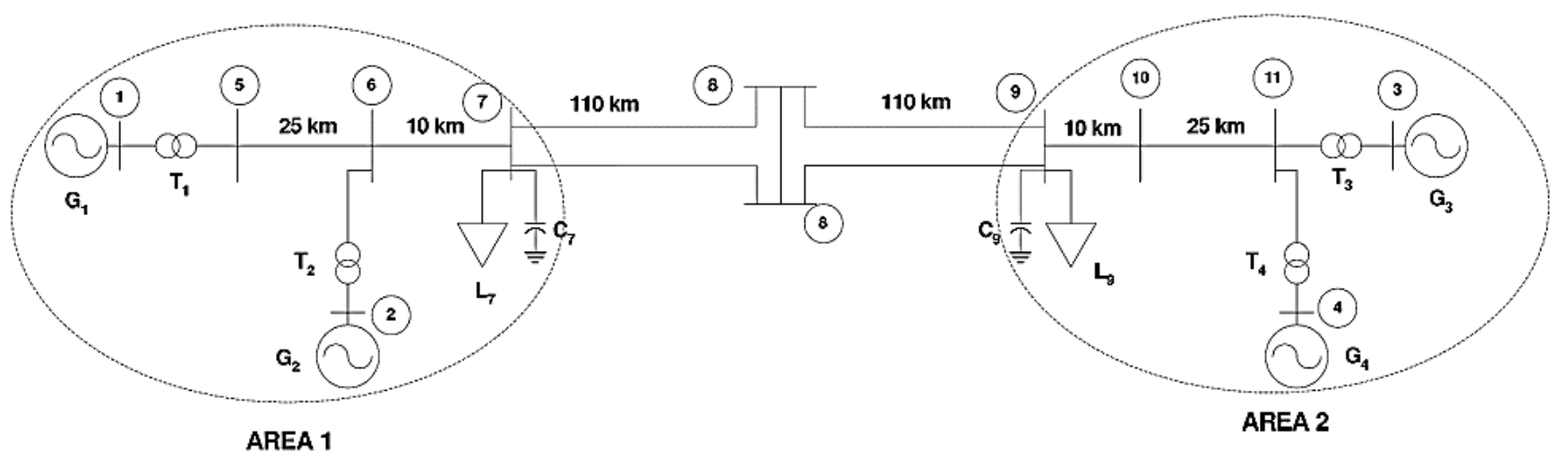

Fig. 1 Two Area Four-Machine power system for Stability Analysis

Now the actual simulation model implemented for analysis of proposed ANFIS controller based power system stabilizer (Hybrid-PSS) for Inter area power oscillation stability is shown in fig.2.Further Fig.3. Shows the internal structure of area- 1 of the study and testing system and fig. 4. depicts the internal configuration of turbine and regular consisting the proposed ANFIS-PSS.

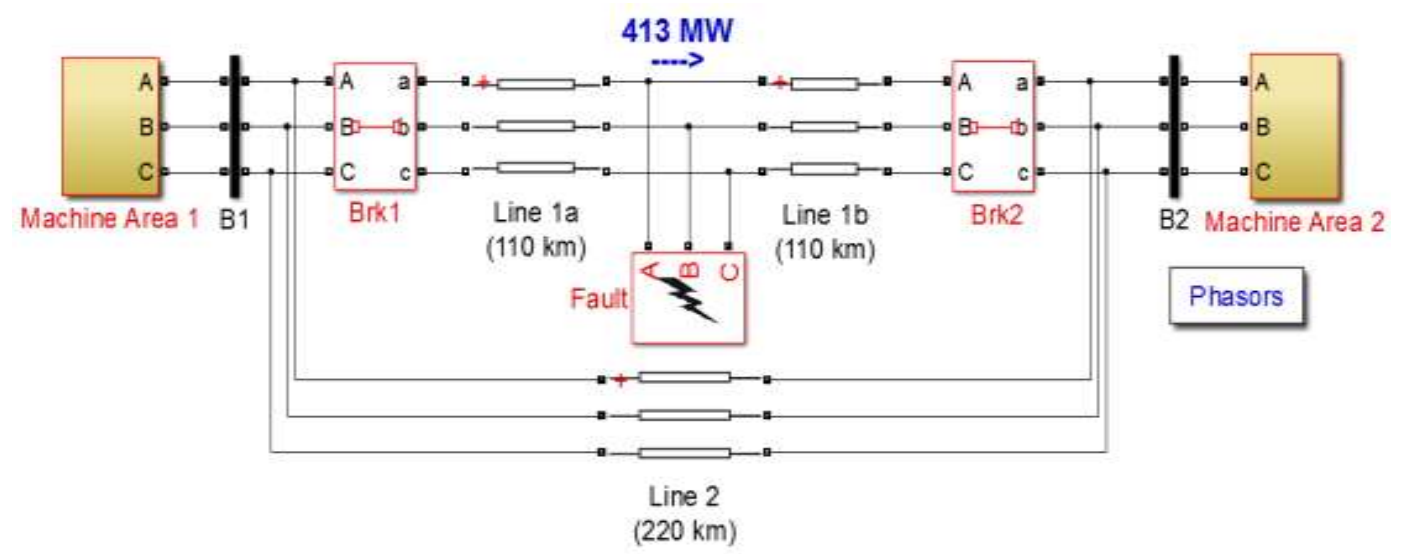

Fig. 2 Actual simulation model implemented ANFIS for Interarea power oscillation stability Analysis.

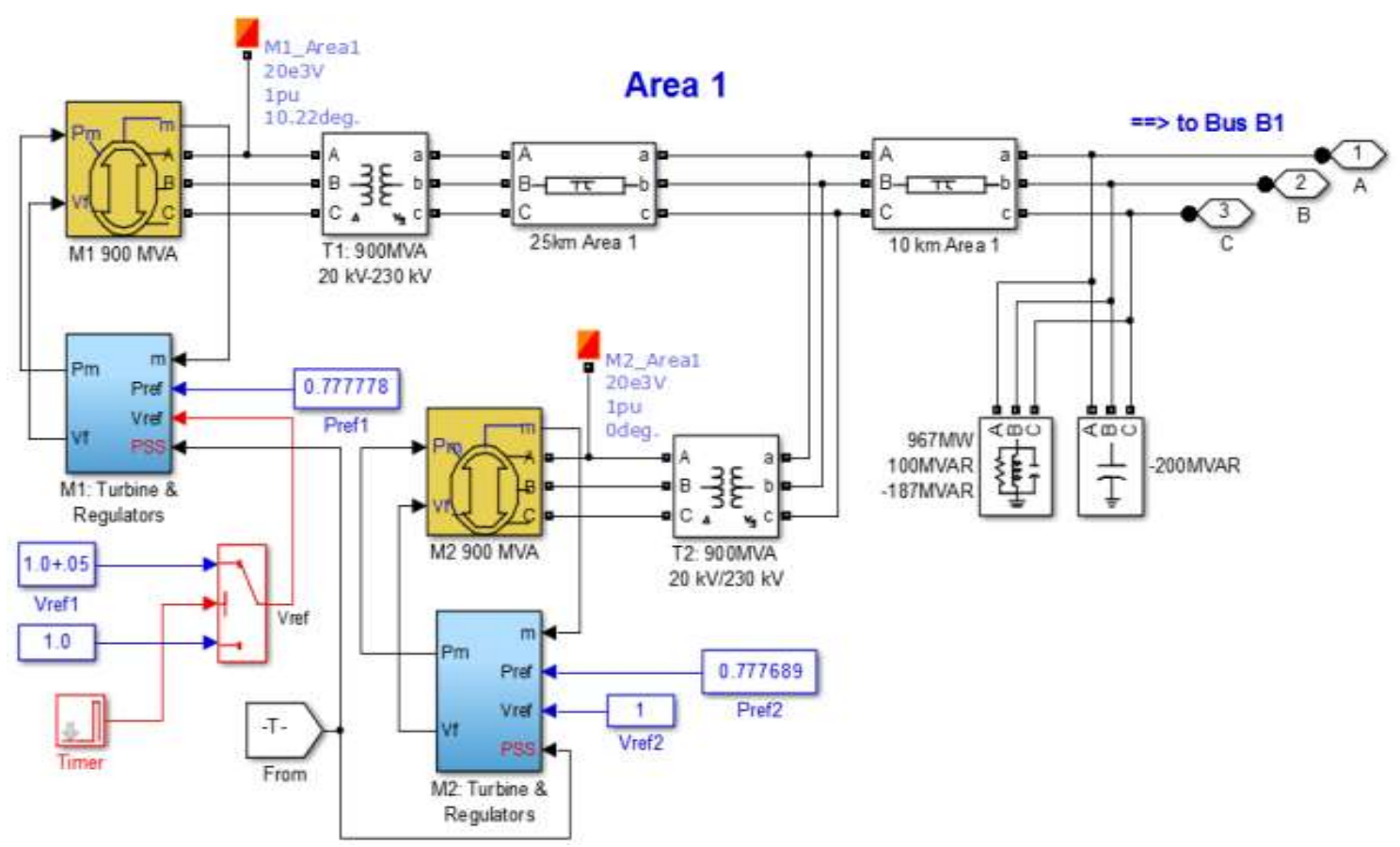

Fig.3 Internal configuration of area 1(subsystem) 


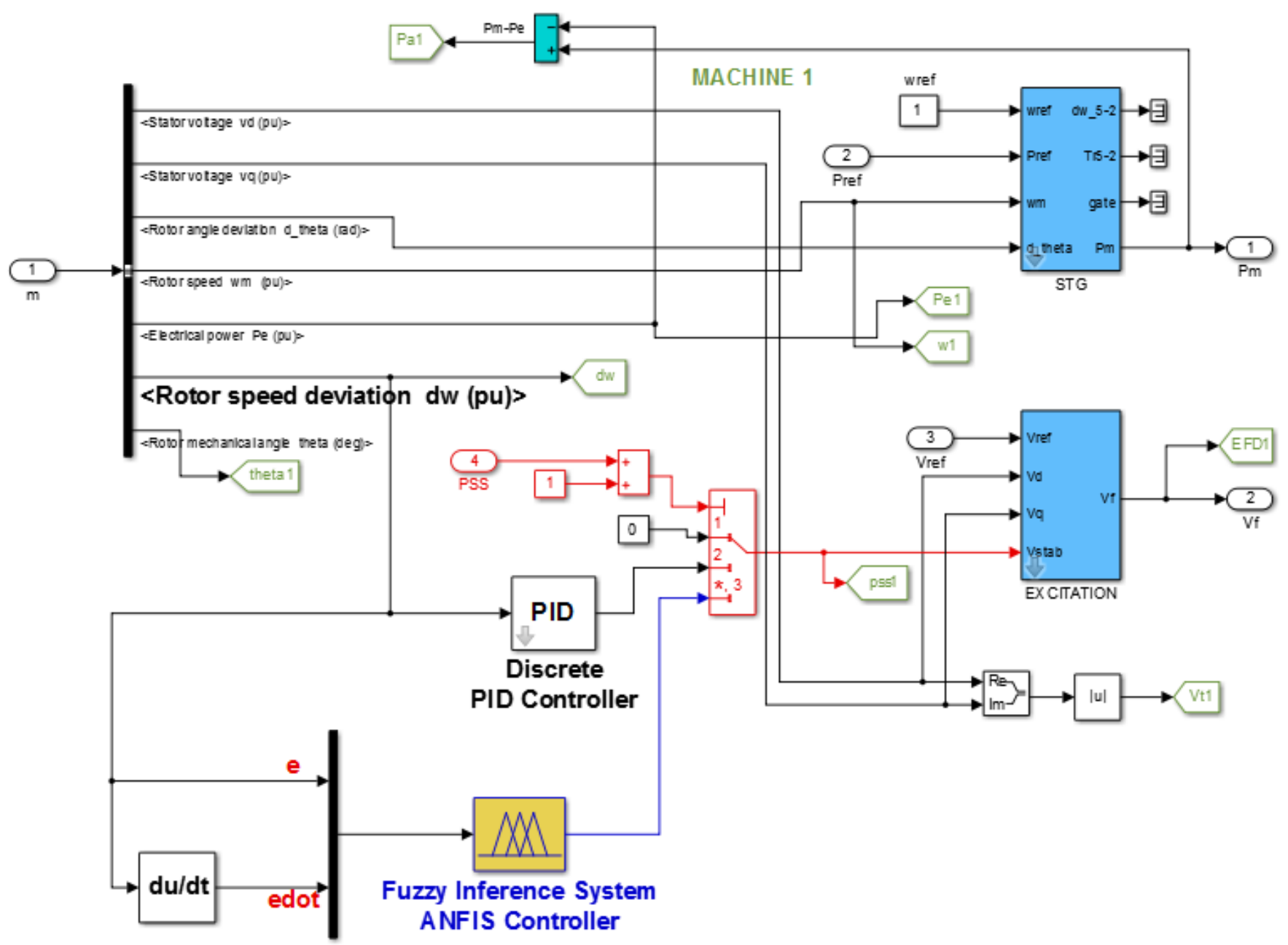

Fig.4 Internal configuration of turbine and regulator with PID-PSS and proposed Hybrid-PSS.

\section{Proposed ANFIS Controller for Inter area \\ Power Oscillation Damping}

During the development of proposed ANFIS controller two input variables have been employed to provide robust performance against power oscillations. Variables, error $(e)$ which is the rotor speed deviation (in pu) has been used as first input variable, while on the same time the rate of change of error signal $(\dot{e})$ has been taken as the second input variable for the designing of proposed controller.

For the development of proposed ANFIS controller following steps have been employed:

Step-1. Obtain the input and outputs of conventional PID controller.

To model required ANFIS controller we need to first analyze the deficiency of PI controller during generation of control signal terminal voltage $\mathrm{V}_{\mathrm{f}}$ in response to the variation in rotor speed deviation. To analyze the controlled terminal voltage $\mathrm{V}_{\mathrm{f}}$ values generated by PID controller, Fig. 5 and fig. 6,Showsthe input and output plot for PID controller particularly for three phase to ground fault respectively.

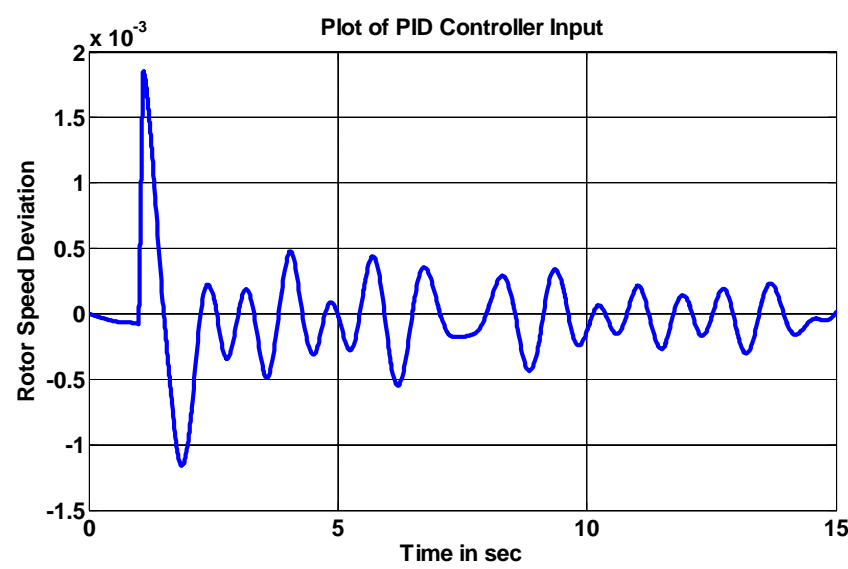

Train the ANFIS for obtained same inputs as used for PID controller and corrected output data.

After designing of the proposed ANFIS controller using aforesaid steps; the membership functions designed for the two inputs error (e) and change rate of error $(\dot{e})$ are shown in Fig. 7 and Fig.8, 


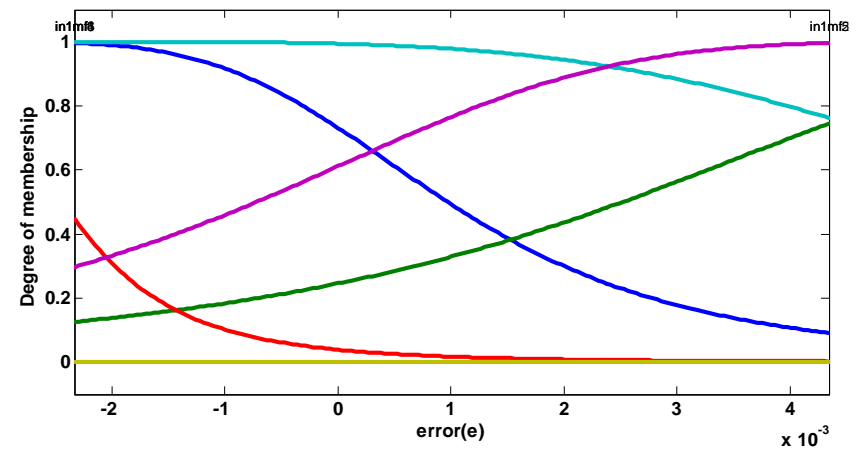

Fig. 7. Membership functions of first input error (e)

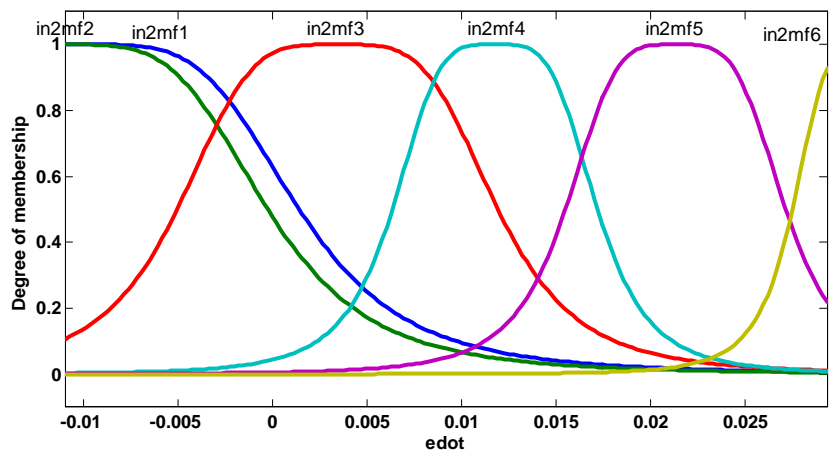

Fig. 8. Membership functions of second input change in error (edot)

\section{SIMULATION RESULTS}

The performance of proposed ANFIS-PSS was evaluated by applying a large disturbance caused by three-phase fault applied at the middle of one tie line at $1 \mathrm{sec}$ and cleared after $0.083 \mathrm{sec}$ by opening the breakers.

To investigate the Inter area power oscillation damping performance of proposed ANFIS-PSS with two-area fourmachine test system, the three phases to ground fault was considered in the simulation studies .A three-phase fault of $0.083 \mathrm{sec}$ duration is simulated at line-1. Fig. 9 shows the plot of active power transfer response of system under without PSS condition. Fig. 10 presents the result of the examined active power transfer response under PID-PSS. While fig. 11 shows the response of active power transfer response with proposed ANFIS controller based power system stabilizer.

\begin{tabular}{|c|c|c|c|}
\hline Parameter & $\mathrm{Kp}$ & $\mathrm{Ki}$ & $\mathrm{Kd}$ \\
\hline $\mathrm{G} 1$ & 30 & 10 & 0.001 \\
\hline $\mathrm{G} 2$ & 10.50 & 0.67 & 0.45 \\
\hline $\mathrm{G} 3$ & 10.50 & 0.67 & 0.45 \\
\hline $\mathrm{G} 4$ & 10.50 & 0.67 & 0.45 \\
\hline
\end{tabular}

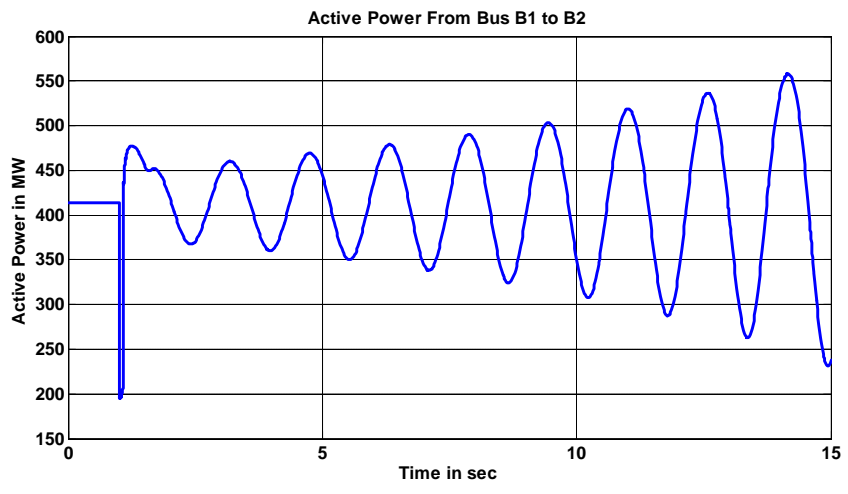

Fig. 9. Active Power transferred under three Phase fault condition without PSS.

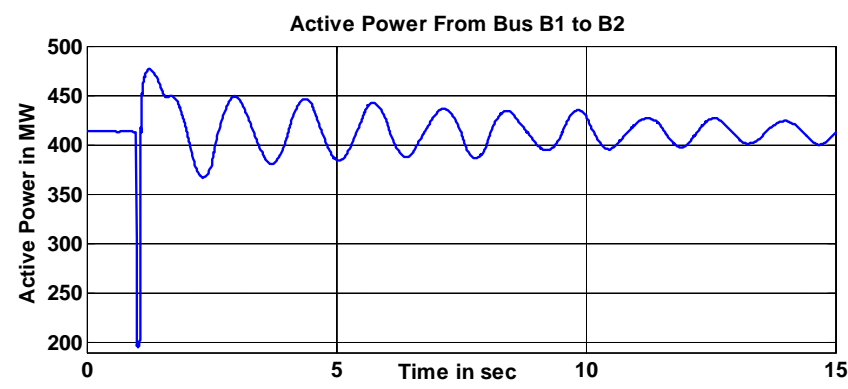

Fig. 10. Active Power transferred under three Phase fault condition with PID-PSS.

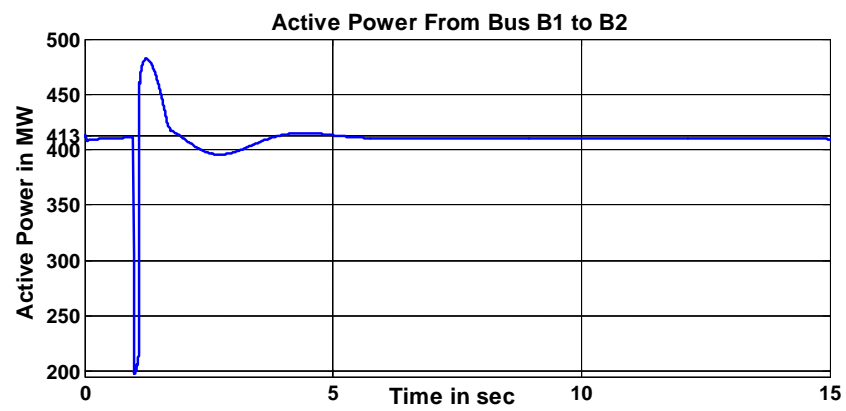

Fig. 11. Active Power transferred under three Phase fault condition with ANFIS-PSS.

From the above plots, the power oscillation damping performance obtained for three phase fault condition without PSS, with PID-PSS and proposed ANFIS based PSS, it is clearly observable that the proposed PSS is highly efficient in providing higher damping in the power oscillation.

\section{CONCLUSION}

Fast and efficient way of achieving inter area power oscillation is developed. Improved dynamic stability of interconnected power system is achieved by damping of active oscillation in two area four machine system with the development of the proposed ANFIS controller based PSS.

After the successful implementation of the proposed ANFIS controller based power system stabilizer (ANFIS-PSS), a complete testing process have been also presented by generating three phase to ground fault on the mid of the 
transmission line. The obtained results shows that the proposed ANFIS controller is capable of damping inter area power oscillations. inter area power oscillation damping capability of proposed ANFIS controller based power system stabilizer (ANFIS-PSS)

In addition to this the results also indicates that, the proposed controller based power system stabilizer takes only $5 \mathrm{sec}$ to completely damp the Inter area power oscillations.

\section{REFERENCES}

[1] PrabhaKundur, Power System Stability and Control, McGraw-Hill, Inc, 1994.

[2] Junbo Zhang; Chung, C.Y.; Shuqing Zhang; Yingduo Han, "Practical Wide Area Damping Controller Design Based on Ambient Signal Analysis," Power Systems, IEEE Transactions on, vol.28, no.2, pp.1687,1696, May 2013.

[3] Hussein, T.; Shamekh, A., "Direct Adaptive Fuzzy Power System Stabilizer for a Multi-machine System," Computer Modeling and Simulation (UKSim), 2013 UKSim 15th International Conference on, vol., no., pp.33,38, 10-12 April 2013.

[4] Qudaih, Y.S.; Mitani, Yasunori; Mohamed, T.H., "Wide-Area Power System Oscillation Damping Using Robust Control Technique," Power and Energy Engineering Conference (APPEEC), 2012 Asia-Pacific , vol., no., pp.1,4, 27-29 March 2012.

[5] Babaei, E.; Golestaneh, F.; Shafiei, M.; Galvani, S., "Design an optimized power system stabilizer using NSGA-II based on fuzzy logic principle," Electrical and Computer Engineering (CCECE), 2011 24th Canadian Conference on, vol., no., pp.000683, 000686, 8-11 May 2011.

[6] Alsafih, H. A.; Dunn, R. W., "Performance of WideArea based Fuzzy Logic Power System Stabilizer," Universities' Power Engineering Conference (UPEC), Proceedings of 2011 46th International, vol., no., pp.1, 6, 5-8 Sept. 2011.

[7] Daryabeigi, E.; Moazzami, M.; Khodabakhshian, A.; Mazidi, M.H., "A new power system stabilizer design by using Smart Bacteria Foraging Algorithm," Electrical and Computer Engineering (CCECE), 2011 24th Canadian Conference on, vol., no., pp.000713, 000716, 8-11 May 2011.

[8] Babaei, E.; Galvani, S.; AhmadiJirdehi, M., "Design of robust power system stabilizer based on PSO," Industrial Electronics \& Applications, 2009. ISIEA 2009. IEEE Symposium on, vol.1, no., pp.325, 330, 4-6 Oct. 2009.

[9] Hadidi, R.; Jeyasurya, B., "Reinforcement learning approach for controlling power system stabilizers," Electrical and Computer Engineering, Canadian Journal of, vol.34, no.3, pp.99, 103, summer 2009.

[10]Huaren Wu; Qi Wang; Xiaohui Li, "PMU-Based Wide Area Damping Control of Power Systems," Power System Technology and IEEE Power India Conference,
2008. POWERCON 2008. Joint International Conference on, vol., no., pp.1, 4, 12-15 Oct. 2008.

[11] Athanasius, G.X.; Pota, H.R.; Subramanyam, P.V.B.; Ugrinovskii, V., "Robust power system stabilizer design using minimax control approach: Validation using Realtime Digital Simulation," Decision and Control, 2007 46th IEEE Conference on, vol., no., pp.2427, 2432, 1214 Dec. 2007.

[12]Hunjan, M.; Venayagamoorthy, G.K., "Adaptive Power System Stabilizers Using Artificial Immune System," Artificial Life, 2007. ALIFE '07. IEEE Symposium on, vol., no., pp.440, 447, 1-5 April 2007.

[13] Dobrescu, M.; Kamwa, I., "A new fuzzy logic power system stabilizer performances," Power Systems Conference and Exposition, 2004. IEEE PES, vol., no., pp.1056, 1061 vol.2, 10-13 Oct. 2004.

[14] V. Vittal, "Consequence and Impact of Electric Utility Industry Restructuring onTransient Stability and SmallSignal Stability Analysis", Proceedings of the IEEE,Vol. 88, No. 2, Feb. 2000. 